\title{
The University of Akron
}

\section{IdeaExchange@UAkron}

Proceedings from the Document Academy

University of Akron Press Managed

December 2017

\section{A Palimpsest of Diné Voices}

Frances Vitali

University of New Mexico, fvitali@unm.edu

Brian C. O'Connor

Visual Thinking Laboratory, College of Information, University of North Texas, brian.oconnor@unt.edu

Please take a moment to share how this work helps you through this survey. Your feedback will be important as we plan further development of our repository.

Follow this and additional works at: https://ideaexchange.uakron.edu/docam

Part of the Critical and Cultural Studies Commons, Gender, Race, Sexuality, and Ethnicity in $\underline{\text { Communication Commons, Information Literacy Commons, and the Interpersonal and Small }}$ Group Communication Commons

\section{Recommended Citation}

Vitali, Frances and O'Connor, Brian C. (2017) "A Palimpsest of Diné Voices," Proceedings from the Document Academy: Vol. 4 : Iss. 2 , Article 3.

DOI: https://doi.org/10.35492/docam/4/2/3

Available at: https://ideaexchange.uakron.edu/docam/vol4/iss2/3

This Conference Proceeding is brought to you for free and open access by University of Akron Press Managed at IdeaExchange@UAkron, the institutional repository of The University of Akron in Akron, Ohio, USA. It has been accepted for inclusion in Proceedings from the Document Academy by an authorized administrator of

IdeaExchange@UAkron.For more information, please contact mjon@uakron.edu, uapress@uakron.edu. 
Ordinarily we think of a palimpsest as a piece of vellum that has had some writing scraped off to provide a surface on which to write something new but yet shows faint traces of the original message. Perhaps the most famous palimpsest today is that of a text of Archimedes scraped away for a prayer book. Here we see the prayer book text running vertically over faint horizontal words. With years of work by digital imaging scientists, classical mathematics specialists, and a host of others, much of the original text is now accessible.

This sense of palimpsest assumes that communication is in written form and that some subsequent message maker values a new message over some existing message enough to attempt to erase the earlier message. Yet there is a significant assumption about communication here - both messages are inscribed on a durable medium. What, though, of communication that does not rely on marks scribed on a durable medium? What

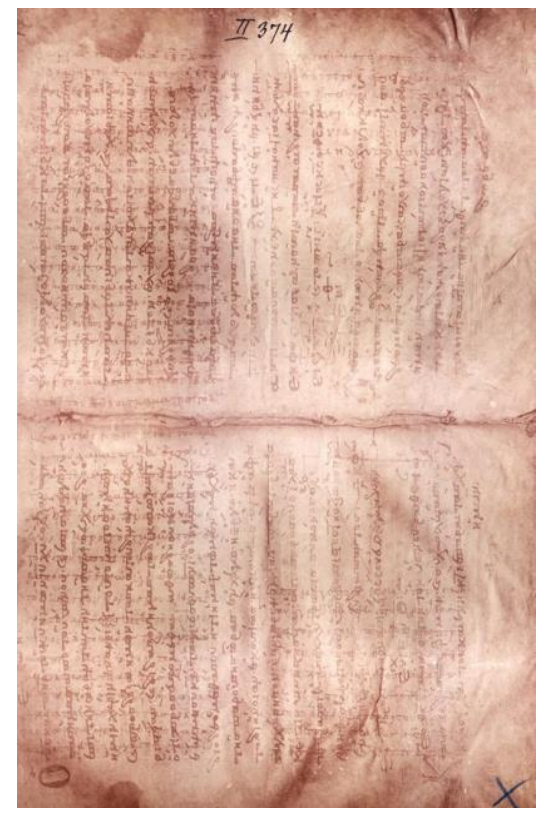
of an intersection between two fundamentally different assumptions about medium of message making? What of conflict between two such systems?

Here we look at a radical form of palimpsest to illuminate our understanding of documents and possible consequences of radically different assumptions about message making.

Stories are an integral part of what defines us as human beings; writing fuses symbols of representation with the preservation of ideas (Levy, 2001). Stories are technological extensions of ourselves as coding systems. However, coding is culturally situated. Diné (a.k.a. Navajo ${ }^{1}$ ) traditional oral stories represent ancestral knowledge, serving as a template for Navajo life and identity (Schwarz, 1997, 2001). Every time an oral story is told, context of representation is a consideration for "context creates meaning" (O’Connor and Wyatt, 2004, p. 139).

In a culture such as the Diné, oral tradition and oral language still resonate within mediated print and digital technologies as a complementarity. There is still a commitment to honoring the voice of the storyteller in American Indian literature,

\footnotetext{
${ }^{1}$ The Nihookaa' Diné (Earth Surface People) or T'aa Diné (The People), i.e. the "five-fingered people," distinguishing them from their ancestors, or more generally, Diné, is the culturally preferred appellation, rather than the colonialized term Navajo.
} 
for colonialist attitudes may still be coded with unchallenged stereotypes, cultural inaccuracies for readers. Bruchac acknowledges, "People often are powerless, alone, afraid; this is because someone else is telling their story for them: 'You are stupid. You are ugly. You are undesirable. You are useless.' Through storytelling, you recognize your real story" (Vitali, 2016, pp. 30-31).

\section{Modeling Storying}

Our neurological consciousness is equivalent to our stories, as our autobiographical self (systems of culture/world view/authoring methods), for they provide the consistency and template with which to compare new experiences (Damasio, 1999). As Anais Nin asserts, referring to the Talmud: "We don't see things as they are; we see them as we are" (Nin, 1960, p. 124).

Modeling this set of problems in a communication/information retrieval setting can provide insight to educators, authors, and researchers wrestling with the impacts of such technological erasure; it may also broaden our understanding of information seeking and retrieval, for similar, if less shocking and obvious, problems exist between many groups. Using Hayes's (1991) notion of communication as dance, its expansion by Kearns and O'Connor (2004), and Vitali's (2004) research on Navajo and cross-cultural notions of storying, we construct an information theoretic model of Navajo storytelling and identity in a cultural milieu with a history of attempting to erase stories and the very technology of storytelling.

\section{Story as Human Technology}

Our "thought flows in terms of stories" and "the brain is a story-seeking, story creating instrument" (Smith, 1990, pp. 62-63). Stories are "a human invention" and "learning 'story' and learning to 'story' involves learning a way of thinking, a way of organizing events and information, a way of knowing” (Rietz, 1988, p. 164). We are stories (King, 2003, p. 2). "We live by stories and we live in them. One way or another we are living the stories planted in us early or along the way, or we are also living the stories we planted - knowingly or unknowingly - in ourselves" (Okri, as cited in King, 2003, p. 153).

Stories are aural, oral, literary human expressions; human extensions and human technologies designed to explain who we are, how we come to know, how we negotiate meaning, and how we communicate. Language is the earliest human technology and stories are a natural extension of who we are as human beings giving meaning to and extracting meaning from our world. Bruce Perry (2017) reminds us that we are storytelling primates. 
Storytelling draws from the right hemisphere of holistic, visual, relational processing; whereas, reading and writing draw from the left hemispheric of more linear, logical, segmented, mechanistic (Schlain, 1998). However, both hemispheres of the brain function collectively. Ong (1982) describes this tension and complementarity of both sides of our brain identifying Western (dominant society) and non-Western (non-dominant society) perspectives. As Burke and Orenstein (1995, p. 75) document, just as the axe was a tool that changed civilization, so too the alphabet and the printing press became the most powerful tools for change thus far.

\section{Erasure}

In a culture such as the Diné, oral tradition and oral language still resonate within mediated print and digital technologies as a complementarity. Indigenous students come from a storied place of coming to know their identity, culture, and language through the orality of language as their first knowledge. As Navajo students navigate a literate society, "we must remember that we come from cultures rooted in the power and beauty of oral tradition and face-to-face storytelling" (Deschenie, 2007, para. 24).

The American Psychological Association and (APA) and American Sociological Association (ASA) acknowledge damaging effects of misrepresentation that continue within Indigenous literature (Reese, 2007, para. 7):

For American Indian people, whose history is not often portrayed accurately, perpetuating stereotypes involving mascots, symbols, images, and personalities permeate documents, thereby miseducating other American Indians and non-American Indians about American Indian culture, society, and spirituality (Gone, 2002; Connolly, 2000; Moses, 1996; Churchill, 1994, Nuessel, 1994; Banks, 1993).

There is still a commitment to honoring whose voice is telling the stories in American Indian literature, for colonialist attitudes may still be coded with unchallenged stereotypes, cultural inaccuracies for readers. Historically, societies authored with writing represent cognitive authority, thereby standardizing the coding system. Literacy emerged as the language of the powerful. For example, American Indian students in boarding schools were punished for speaking their tribal languages. Yet, conveniently, during World War II, Diné language and other Native languages were used as a secret code and weapon that contributed to winning the war. One Navajo Code Talker recognized the significance of Diné 
language in the war effort stating that without the help of the Navajo language, "Americans would be eating with chopsticks" (personal communication, J. Whitehorse, April 11, 2000).

Every time an oral story is told, context of representation is always a consideration. As an act of homo faber and technologists, writing fuses symbols of representation with the preservation of ideas (Levy, 2001). Stories are technological extensions of ourselves as coding systems. However, coding is culturally situated. Diné traditional oral stories represent ancestral knowledge serving as a template for Diné life and identity (Schwarz, 1997, 2001). Historically, societies that authored with writing represented the dominant status quo, thereby standardizing the coding system. Literacy emerged as the language of the powerful. Historical examples include legally preventing slaves to read and write in the Southern United States and punishing American Indian students in boarding schools for speaking their tribal languages. The American Sociological Association recognizes that racial prejudice, stereotypes, and discrimination are socially created phenomena that are harmful to American Indians and other people of color (Reese, 2007, paras. 7-8).

As technological extensions of ourselves, stories are coding systems. The oral stories of the Long Walk (Hwéeldi) reveal the mass incarceration of Navajos and Mescalero Apaches in 1864-1968. Government-written documents are juxtaposed against passed down oral stories committed to print and reveal a clash of coding systems and the context of representation.

\section{Cultural Palimpsest}

Historical accounts of the forced Long Walk (Hwéeldi), on Navajos to Fort Sumner (Bosque Redondo) prison camp is coded with "bipolar perspectives" (Roberts, 1997, para. 21). A governmental perspective:

The Navajoes. That fierce and untameable tribe of red-skins, the Navajoes, whom we have been fighting for the last eighteen years, are reported to have lately surrendered to our forces in New Mexico; and on the heels of this news, we have the announcement from Washington that an appropriation of one hundred thousand dollars is asked for Congress for the subsistence of the tribe. ... In future it is proposed to give each individual of the tribe, numbering seven thousand in all, a daily allowance of one pound of flour and one pound of fresh meat, which, if they consume it all, will, it is thought leave them little stomach for the fight. But the Navajos are very treacherous, and pay little regard to treaties or agreements with white men. Col. Doniphan beat them and made a treaty with them in 1846, but they soon 
forgot it; Col. Washington did the same things in 1849, with the same result; Col. (subsequently Major-General) Sumner repeated the operation in 1851, but we have heard of their depredations almost every year since. The fact is, fighting has been the ceaseless and immemorial occupation of the Navajos; and we fear that the bread and beef now furnished to them will only give them strength and muscle to fight us again the coming summer. (New York Times, 1864)

Roberts (1997, paras. 16-17) offers the following coded dissonance:

In March 1864, one officer, leading a party of almost 950 men, women and children, arrived at Bosque Redondo to admit that 110 had died en route; and claimed that the 'Navajos were greatly delighted and expressed great satisfaction with what they saw.'

The Navajo oral tradition paints a markedly different picture. A recurrent theme of horror, passed on to the grandchildren of Navajos who made the Long Walk, held that stragglers in the procession, including pregnant women, children and the aged, were simply shot and left unburied beside the trail.

Interestingly no names were kept of the Hwéeldi internees: only tally marks. However, the Army did maintain records of every soldier stationed at Fort Sumner and some of their family members (Yurth, 2014).

Lake Valley community members shared their family stories about the Long Walk passed down from their great grandparents (Diné of the Eastern Region of the Navajo Reservation, 1991):

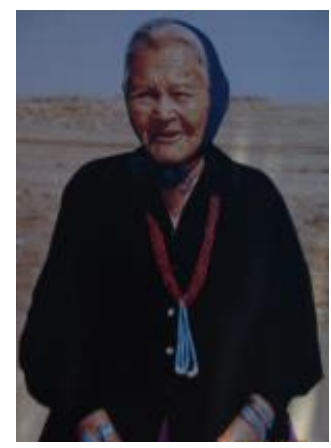

\section{Mary Pioche's Story excerpt:}

When men and women talk about Hwéeldi, they say it is something you cannot really talk about, or they say they would rather not talk about it. Every time their thoughts go back to Hwéeldi, they remember their relatives, families, and friends who were kicked by the enemies. They watched them die, and they suffered with them, so they break into tears and start crying. That is why we only know segments of stories, pieces here and there. Nobody really knows the whole story about Hwéeldi. (p. 99) 


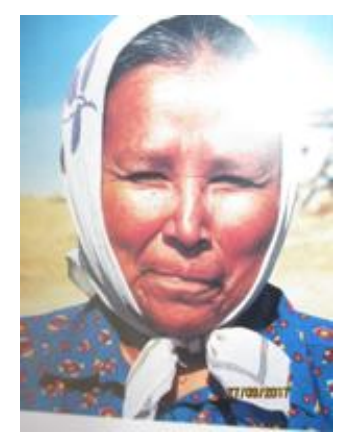

Jane Hasteen's Story excerpt:

At Hwéeldi, the Navajos suffered from many hardships....During that time there was no written history as there is today. The stories were told orally. It is hard to remember everything that happened and was told to us about the time that the Navajos were rounded up and marched to Hwéeldi ...maybe over one hundred years ago now. My grandmother said that when the Navajos were released, they were few in number. From the few Navajos who survived, today's population has grown. (p. 73)

\section{Helen Begay's Story excerpt:}

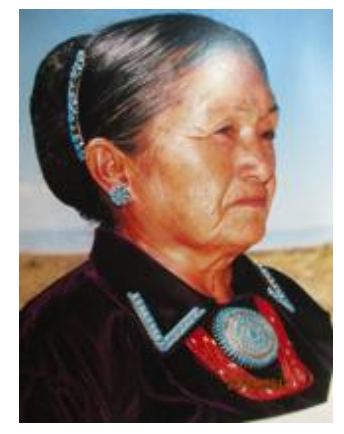

The Navajos promised the white men that they would put their children in schools, which were provided by the United States Government. When the people got back to Fort Defiance, food was distributed among the Navajo families. Some of the food included flour, bacon, and coffee. The people did not know how to prepare these foods. Some people ate the bacon raw and the flour without mixing it, and chewed the coffee beans without boiling them. Many Navajos got sick from the improper preparation of this foreign food. (p. 13)

\section{Jane Begay’s Story excerpt:}

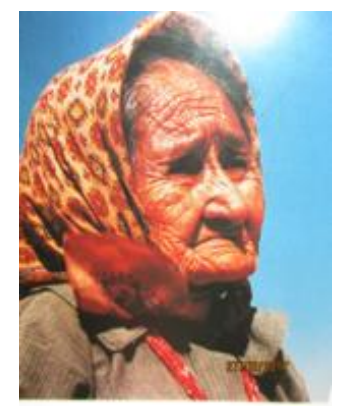

The Navajos lost many of their people during that time. Many young girls were captured. Because the men were the ones who did most of the raiding, the Mexicans killed many of the boys. Sometimes they would cut a baby's throat right in the cradleboard. (p. 18)

Joe Billy's Story excerpt: 


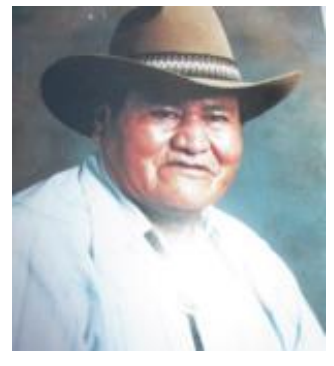

When my grandmother told us these stories, she said, "We suffered at Hwéeldi, my grandchildren, and you will be living the same life yourselves someday. You must remember these stories as you live" (p. 47).

Several days before our DOCAM 2017 presentation, Bessie Epaloose, (resident of Lake Valley community on Navajo Nation) where I (Frances) lived and taught for 12 years) stopped by my office to say hello. Having attended a Navajo Puberty Ceremony (Kinaaldá) over the weekend with her daughter, who attends Eastern New Mexico State University, Bessie shared the advice she gave her daughter:

I shared with her about what my grandmother who went to Fort Sumner (Long Walk) told my mother and what my mother taught me. My mother told me stories about my grandmother and the Long Walk, which was not that long ago. Now I am teaching my daughter, and I am taking it to another level. It is still taking place in homes. I always teach her something when she comes home. I told her to always be prepared: have your IDs in place; your shoes ready by your bed; gas tank full; have an emergency plan wherever you are; don't sleep late; be on the alert. When you come home, you can relax because your parents are the ones who will be alert for you. These stories (teachings) are still taking place in homes. (personal communication, B. Epaloose, September 25, 2017)

Bessie's advice to her daughter reflects the generational advice passed down

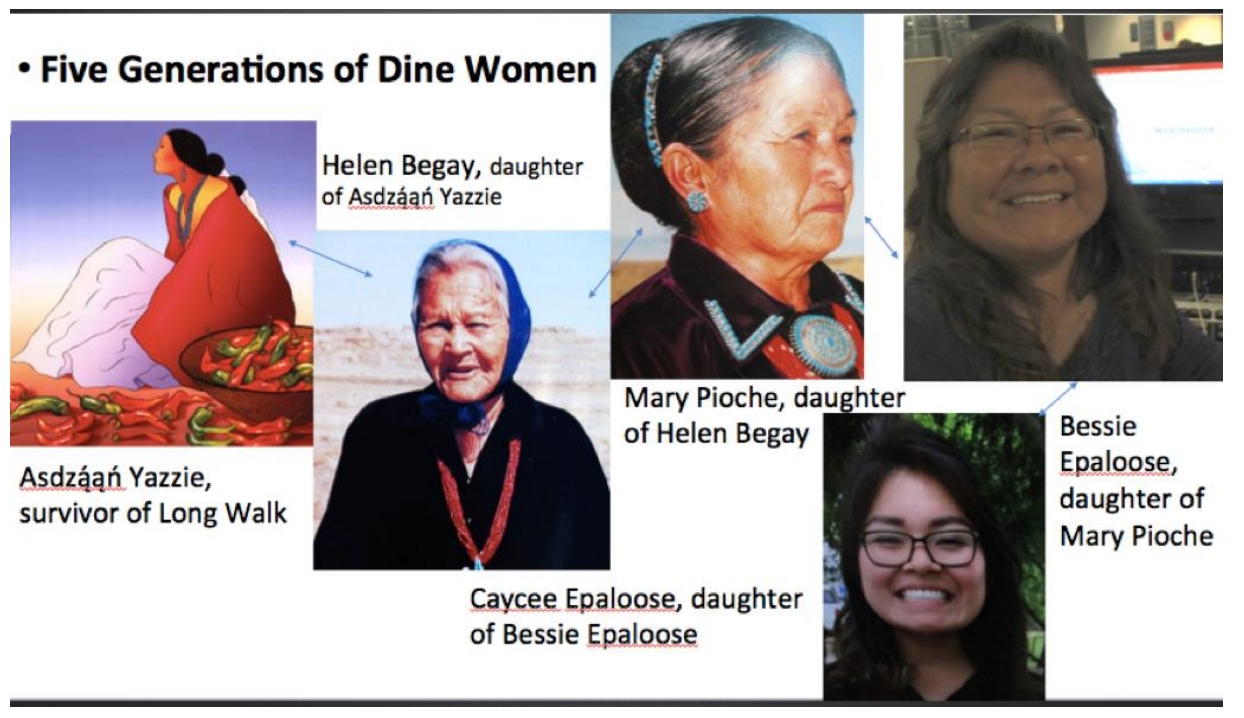


through her family. This palimpsest of cultural coded advice reflects the historical trauma embedded in the language of survival and protection from enemies dating back to the Long Walk.

Artist and storyteller Larry King (personal communication, September 27, 2017) explains the significance of his images on his commissioned poster Return to Diné Original Thought and Identity, which appears to the right:

Drawing from ancient Navajo lifeways and knowledge, we still carry this with us even though we have gone through a lot of oppression. The center picture in the poster represents the Bosque Redondo era. Above that, the top picture represents the modern Navajo and Navajo bureaucrats who are part of the leadership and governance talking to Navajos who have gone through the boarding school experience and have been educated. There is

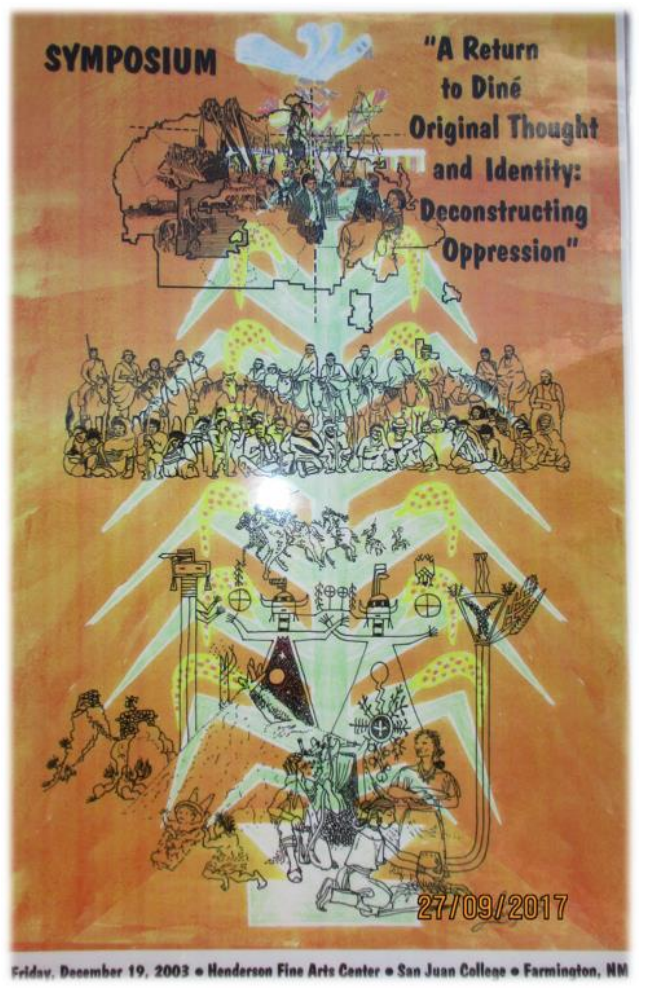
representation of coal mining, transportation with horses and farming. At the same time, we have lot of modern intrusion of how society is changing through the technology of $21^{\text {st }}$ century.

Bottom one represents the fundamental knowledge of traditional Navajo world view integrated into the ceremonial context of stories, songs and legends. They talk about how we came into this world and introduces all the concepts of how we came into this world; the Four Cardinal Directions; Female and Male working together; Children in cradleboards. Everything has knowledge in it.

Then the refugee era happened. Spanish were warring with Navajos and Pueblos had been integrated into the Spanish concept of slavery. Some Pueblos who were introduced into slavery fled with the Navajo, Southeast of Farmington, to Largo Canyon. 
In the background is the corn post represented and the bluebird is on top and this carries on the traditional Navajo strong worldview and how to properly interact. Everything is integrated. This is represented in the background. Even though we have gone through a lot, we still have a lot of knowledge integrated from traditional Navajo concepts. That is what I was representing when I drew this.

We have looked into Diné voices as a provocation, an edge case for expanding the notion of communication as a dance, as suggested by Kearns and O'Connor (2004). In that model the communication dance partners make certain assumptions about one another. If the communication is synchronous or nearly so, each partner might make adjustments to the assumptions about the other. As time, distance, culture, and other settings for assumptions become more distant, adjustments requirement greater expenditure of resources. The Rosetta Stone made a pronouncement of royal and deific significance and even had the forethought - or proactive adjustment making - to use codes in three languages. Yet, centuries later, assumptions had changed sufficiently that the hieroglyphs were of little use and it took twenty years for Champollion to decode them as both pictographic and phonetic. For a time in the eighteenth century, the Rosetta Stone was a message - a document, surely, but of little communicative power without a code.

We might say that we have a similar sort of distance between coding systems in looking at Diné document making. The message is not simply encoded in a string of words that happen to be spoken instead of written; rather, the message is the constellation of sounds, cultural activities, methods of propagating and reintegrating the messaging system over time. Patrick Wilson's (1968) notion of families of documents seems fitting here.

Seeing the consequences of some of the interactions between one messaging system and another very different system in our own recent past may give us some ways of thinking about what is happening now with Diné document making. Who guides the making of print children's books that speak authentically to younger generations within and outside of the Diné community? Were boarding schools and other practices of erasure a form of weaponizing differences in communication systems that might be generalizable? What can an approach to documents based on notnecessarily linear construction illuminate for document systems based on linear inscriptions? Can we look to such different document systems as a pathway bringing forth the faint traces of the palimpsest?

\section{References}


Damasio, A. (1999). The feeling of what happens: Body and emotion in the making of consciousness. Orlando, FL: Harcourt.

Deschenie, T. (2007, November 15). Why we are sticking to our stories. Tribal College Journal, 19(2). Retrieved from http://www.tribalcollegejournal.org/sticking-stories/

Diné of the Eastern Region of the Navajo Reservation. (1991). Oral stories of the Long Walk: Hwéeldi Baa Hané. Crownpoint, NM: Lake Valley Navajo School.

Hayes, R. M. (1991). Measurement of information. Information Processing \& Management, 29(1), 1-11.

Kearns, J., \& O’Connor, B. (2004). Dancing with entropy: form attributes, children, and representation. Journal of Documentation, 60(2), 144-163.

King, T. (2003). The truth about stories: A native narrative. Minneapolis, MN: University of Minnesota Press.

Levy, D. M. (2001). Scrolling forward: Making sense of documents in the digital age. New York: Arcade Publishing.

New York Times. (1864, April 9). The Navajoes. The New York Times, p. 4. Retrieved from https://utahindians.org/Curriculum/pdf/HSnavajo.pdf

Nin, A. (1960). Seduction of the minotaur. Chicago, IL: Swallow Press.

O’Connor, B. C. \& Wyatt, R. B. (2004). Photo provocations: Thinking in, with, and about photographs. Lanham, MD: The Scarecrow Press.

Ong, W. (1982). Orality and literacy: the technologizing the word. New York: Routledge.

Perry, B. (2017). How the brain learns best: Easy ways to gain optimal learning in the classroom by activating different parts of the brain. Retrieved from http://teacher.scholastic.com/professional/bruceperry/brainlearns.htm

Reese, D. (2007, November 4). Stereotypes, children's books, and the mental health and well being of ALL children. Retrieved from https://americanindiansinchildrensliterature.blogspot.com/2007/11/mental-healthand-well-being-of-all.html

Rietz, S. (1988). Using oral literature in the classroom. In J. Reyhner (Ed.), Teaching the Indian child: A bilingual/multicultural approach. Billings: Eastern Montana College.

Roberts, D. (1997). The long walk to Bosque Redondo: officials called it a reservation, but to the conquered and exiled Navajos it was a wretched prison camp. Smithsonian, 28(9), 46-56.

Schlain, L. (1998). The alphabet versus the goddess: The conflict between word and image. New York: Viking.

Smith, F. (1990). To think. New York: Teachers College Press.

Schwarz, M. T. (1997). Molded in the image of Changing Woman: Navajo 
views on the human body and personhood. Tuscon: University of Arizona Press.

Schwarz, M. T. (2001). Navajo lifeways: Contemporary issues, ancient knowledge. Norman: University of Oklahoma Press.

Vitali, F. (2004). Navajo cyber-sovereignty: Digital Dine' weaving the worldwide web into an oral culture (Doctoral dissertation, Emporia State University). Available from ProQuest Dissertations and Theses database. (UMI No: 118992)

Wilson, P. G. (1968). Two kinds of power: A essay on bibliographic control. Berkeley: University of California Press.

Yurth, C. (2014, October 2). Making peace with a painful past. Navajo Times. Retrieved from http://navajotimes.com/news/2014/1014/100114longwalk.php 